\title{
Five-Year Longitudinal Study of Neck Vessel Cross-Sectional Area in Multiple Sclerosis
}

\author{
(D). Pelizzari, (DD. Jakimovski, (D) M.M. Laganà, (D) N. Bergsland, (D). Hagemeier, (D) G. Baselli, (D)B. Weinstock-Guttman, and \\ (D) R. Zivadinov

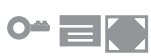

\begin{abstract}
BACKGROUND AND PURPOSE: Alterations of neck vessel cross-sectional area in multiple sclerosis have been reported. Our aim was to investigate the evolution of the neck vessel cross-sectional area in patients with MS and healthy controls during 5 years.
\end{abstract}

MATERIALS AND METHODS: Sixty-nine patients with MS (44 relapsing-remitting MS, 25 progressive MS) and 22 age- and sex-matched healthy controls were examined twice, 5 years apart, on a 3T MR imaging scanner using 2D neck MR angiography. Cross-sectional areas were computed for the common carotid/internal carotid arteries, vertebral arteries, and internal jugular veins for all slices between the C3 and C7 cervical levels. Longitudinal cross-sectional area differences at each cervical level and the whole-vessel course were tested within study groups and between patients with MS with and without cardiovascular disease using mixed-model analysis and the related-samples Wilcoxon singed rank test. The Benjamini-Hochberg procedure was performed to correct for multiple comparisons.

RESULTS: No significant cross-sectional area differences were seen between patients with MS and healthy controls at baseline or at follow-up. During the follow-up, significant cross-sectional area decrease was found in patients with MS for the common carotid arteryICAs (C4: $P=.048 ; \mathrm{C7}: P=.005$; whole vessel: $P=.012$ ), for vertebral arteries (C3: $P=.028 ; C 4: P=.028 ; \mathrm{C7}: P=.028$; whole vessel: $P=$ .012 ), and for the internal jugular veins (C3: $P=.014 ; \mathrm{C} 4: P=.008 ; \mathrm{C} 5: P=.010 ; \mathrm{C} 6: P=.010 ; \mathrm{C7}: P=.008$; whole vessel: $P=.002)$. Patients with MS without cardiovascular disease had significantly greater change than patients with MS with cardiovascular disease for internal jugular veins at all levels.

CONCLUSIONS: For 5 years, patients with MS showed significant cross-sectional area decrease of all major neck vessels, regardless of the disease course and cardiovascular status.

ABBREVIATIONS: CCA = common carotid artery; CSA = cross-sectional area; CVD = cardiovascular disease; EDSS = Expanded Disability Status Scale; HC = healthy controls; $\mathrm{HC}_{\mathrm{CVD}}=$ healthy controls with cardiovascular disease; $\mathrm{HC}_{\text {nocvD }}=$ healthy controls without no cardiovascular disease; IJV = internal jugular vein; $\mathrm{IQR}=$ interquartile range; $\mathrm{MS}_{\mathrm{CVD}}=$ patients with $\mathrm{MS}$ with cardiovascular disease; $\mathrm{MS}_{\text {nocvD }}=$ patients with MS without cardiovascular disease; $\mathrm{RRMS}=$ relapsingremitting MS; PMS = progressive MS; VA = vertebral artery WV = whole vessel; MS = multiple sclerosis; ICA = internal carotid artery

ultiple sclerosis is a chronic immune-mediated inflammatory disease of the central nervous system characterized by
Received April 19, 2018; accepted after revision June 6

From the Department of Electronics Information and Bioengineering (L.P., G.B.), Politecnico di Milano, Milan, Italy; Istituto di Ricovero e Cura a Carattere Scientifico (L.P., M.M.L.), Fondazione Don Carlo Gnocchi ONLUS, Milan, Italy; and Buffalo Neuroimaging Analysis Center (D.J., N.B., J.H., R.Z.), Department of Neurology, Jacobs School of Medicine and Biomedical Sciences; Jacobs Multiple Sclerosis Center (B.W.-G.), Department of Neurology, School of Medicine and Biomedical Sciences; and Center for Biomedical Imaging at Clinical Translational Science Institute (R.Z.), University at Buffalo, State University of New York, Buffalo, New York. Research reported in this publication was funded in part by the National Center for Advancing Translational Sciences of the National Institutes of Health under award Number ULITR001412 and, in part, by the Annette Funicello Research Fund for Neurological Diseases and internal resources of the Buffalo Neuroimaging Analysis Center. In addition, we received support from the Jacquemin Family Foundation.

The content is solely the responsibility of the authors and does not necessarily represent the official views of the National Institutes of Health. demyelination and neurodegeneration. MS does not seem to be triggered by a single specific factor, and there is mounting evidence that genetic, environmental, and cardiovascular risk factors play an important role in the development of the disease. ${ }^{1}$

Although still elusive, the involvement of the vascular component in MS has been investigated across time from different points of view. $^{2-5}$ The disruption of the blood-brain barrier and the perivenular topography of MS lesions are recognized as well-established features of MS pathology. ${ }^{2}$ Furthermore, MS lesions

\footnotetext{
Please address correspondence to Robert Zivadinov, MD, PhD, University of Buffalo, Department of Neurology, Jacobs School of Medicine and Biomedical Sciences, University at Buffalo, 100 High St, Buffalo, NY 14203; e-mail: rzivadinov@bnac.net

- Indicates open access to non-subscribers at www.ajnr.org

$\equiv$ Indicates article with supplemental on-line tables and appendix.

Indicates article with supplemental on-line photo.

http://dx.doi.org/10.3174/ajnr.A5738
}

AJNR Am J Neuroradiol 39:1703-09 Sep 2018 www.ajnr.org 
have been observed to be most commonly located in watershed areas of low arterial blood supply, ${ }^{3}$ while in vitro experiments revealed that neural ischemia triggers tight junction disruption, increasing endothelial permeability. ${ }^{4}$ Recently, alterations of neurovascular coupling have also been reported in terms of impaired cerebrovascular reactivity. ${ }^{5}$

In addition, the presence of vascular comorbidities, such as hypertension, dyslipidemia, diabetes, and heart disease, has been shown to be associated with more severe disability, ${ }^{6,7}$ increased lesion burden, ${ }^{8}$ higher risk of relapse, ${ }^{9}$ greater brain atrophy, ${ }^{10,11}$ and increased risk of stroke and heart failure ${ }^{12}$ in patients with MS.

The association of MS with systemic diseases affecting the cardiovascular system suggests that vascular involvement in the pathology may not be limited to only the neurovascular interface. Because extracranial structural changes impact intracranial pressure and hemodynamics, ${ }^{13}$ the investigation of the main routes of brain blood supply and drainage might help to better understand the involvement of the vascular component in MS.

In the past 10 years, some studies have investigated internal jugular vein (IJV) structure and hemodynamics in MS. However, contrasting results were reported, ${ }^{14-16}$ and it was not possible to unequivocally conclude that patients with MS have a higher prevalence of IJV abnormalities with respect to healthy individuals. A recent large study shifted the focus of investigation from neck veins to the main arterial pathways of brain supply, showing reduced cross-sectional area (CSA) of the internal carotid artery and vertebral artery (VA) in patients with MS compared with healthy controls (HC). ${ }^{17}$

No longitudinal studies of neck vessel CSA have been reported in the literature so far. Thus, it is not clear whether altered neck vessel CSA is a primary or secondary phenomenon in MS. Therefore, the aim of this study was to investigate the evolution of ICA, VA, and IJV CSAs during 5 years in a group of patients with MS and HC. We also aimed to examine differences in neck vessel CSA evolution between patients with relapsing-remitting MS (RRMS) and progressive MS (PMS). Finally, we examined changes in the CSA across time in relation to cardiovascular comorbidities.

\section{MATERIALS AND METHODS}

\section{Study Design and Population}

The subjects are part of an ongoing prospective, longitudinal study of cardiovascular, environmental, and genetic risk factors in MS. ${ }^{18}$ At baseline assessment, patients with MS and HC (an approximately 3:1 ratio) were originally enrolled at our center between 2009 and 2014. ${ }^{19}$ The inclusion criteria for this substudy of cardiovascular, environmental, and genetic factors in MS were the following: 1) being a patient with RRMS or PMS, according to the criteria of Lublin and Reingold ${ }^{20}$ or a healthy control at baseline examination; 2) 5-year follow-up from initial enrollment in the cardiovascular, environmental, and genetic study; 3) having neck MR imaging at baseline and follow-up using the same 3T scanner and protocol; 4) 18-75 years of age; and 5) a physical/ neurologic examination within 30 days from the standardized MR imaging study protocol. Exclusion criteria were the following: 1) the presence of a relapse and steroid treatment within the 30 days preceding study entry; 2) pre-existing medical conditions known to be associated with brain or neck pathology; or 3) pregnancy.

Demographic and clinical information was collected for all participants. The body mass index was computed for each subject, and smoking status was recorded. For patients with MS, disability was quantified with the Expanded Disability Status Scale (EDSS) by an experienced neurologist. Furthermore, both MS and HC groups were split into 2 subgroups (ie, patients with MS with and without cardiovascular disease $\left[\mathrm{MS}_{\mathrm{CVD}}\right.$ and $\left.\mathrm{MS}_{\text {noCVD }}\right]$, healthy controls with and without cardiovascular disease $\left[\mathrm{HC}_{\mathrm{CVD}}\right.$ and $\left.\mathrm{HC}_{\text {noCVD }}\right]$ ). Subjects who presented with hypertension and/or heart disease and/or hyperlipidemia and/or diabetes were classified as subjects with cardiovascular disease (CVD).

The study was approved by local institutional review board of the University at Buffalo, and all participants provided written informed consent.

\section{MR Imaging Acquisition}

All participants were scanned twice, 5 years apart, with a 3T Signa Excite HD 12.0 TwinSpeed 8-channel scanner (GE Healthcare, Milwaukee, Wisconsin), using an 8-channel head and neck coil (HDNV; Medrad, Pittsburgh, Pennsylvania). No hardware and software changes occurred during the follow-up. The MR imaging examination consisted of a 2D neck time-of-flight MR angiography, which is described in the On-line Appendix.

\section{MR Imaging Analysis}

Image quality control was performed by an experienced operator. Segmentation of the left and right common carotid arteries-internal carotid arteries (CCA-ICAs), VAs, and IJVs was performed semiautomatically for all slices between the C2-C3 and C7-T1 intervertebral spaces with the Jim 6.0 software package (http:// www.xinapse.com/home.php). Specifically, the vessel contour was drawn by an operator on a single axial slice using the edgedetection and contour-following algorithm and propagated on the other slices with edge-seeking and $3 \mathrm{D}$ propagation modes. ${ }^{21}$ The operator was blinded to the group status and verified the segmentation results, manually editing them, if necessary. Then, neck vessel CSA was computed for each segmented slice, and CSA-to-slice curves were resampled to obtain the same number of measures (ie, samples) for all the subjects, as described previously. ${ }^{22}$ More details about segmentation and resampling methodology are reported in the On-line Appendix.

For each MRA image, CSA measures of the left and right corresponding vessels were summed at each sample to derive total CCA-ICA, VA, and IJV CSA values. Change in CSA ( $\triangle$ CSA) during the 5 years was computed for all total CSA values by subtracting the total CSA at baseline from the corresponding total CSA at follow-up.

\section{Statistical Analysis}

All statistical analyses were performed with SPSS (Version 24; IBM, Armonk, New York). Demographic and clinical differences between groups and subgroups were assessed at baseline with the Fisher exact test, Student $t$ test, and Mann-Whitney $U$ test, as appropriate. The normality of data was assessed with the Shapiro- 


\begin{tabular}{|c|c|c|c|c|c|c|}
\hline & $\mathrm{HC}(n=22)$ & MS $(n=69)$ & $\begin{array}{c}\text { RRMS } \\
(n=44)\end{array}$ & $\begin{array}{c}\text { PMS } \\
(n=25)\end{array}$ & $\begin{array}{l}\text { HC vs MS } \\
\text { ( } P \text { Value) }\end{array}$ & $\begin{array}{c}\text { RRMS vs PMS } \\
\text { (P Value) }\end{array}$ \\
\hline Female (No.) (\%) & $18(81.8)$ & $48(69.6)$ & $28(63.6)$ & $20(80.0)$ & $.411^{\mathrm{a}}$ & $.184^{\mathrm{a}}$ \\
\hline Age (yr), (median) (range) & $48.0(17.7-73.3)$ & $50.3(18.8-68.29)$ & $45.6(18.8-68.3)$ & $58.3(33.1-66.9)$ & $.240^{\mathrm{b}}$ & $<.001^{\mathrm{c}, \mathrm{d}}$ \\
\hline BMI (median) (range) & $25.1(18.1-44.9)$ & $27.3(19.0-44.9)$ & $26.4(19.0-44.9)$ & $28.97(22.5-43.1)$ & $.104^{c}$ & $.128^{c}$ \\
\hline Disease duration (yr) (median) (range) & NA & $13(0-37)$ & $9.5(0-35)$ & $20.0(1-37)$ & NA & $.001^{\mathrm{c}, \mathrm{d}}$ \\
\hline EDSS (median) (range) & NA & $2.5(0-8)$ & $1.5(0.0-6.5)$ & $6.0(1.5-8.0)$ & NA & $<.001^{\mathrm{c}, \mathrm{d}}$ \\
\hline Hypertension (No.) (\%) & $4(18.2)$ & $8(11.6)$ & $2(4.5)$ & $6(24.0)$ & $.474^{\mathrm{a}}$ & $.023^{\mathrm{a}, \mathrm{d}}$ \\
\hline Heart diseases (No.) (\%) & $1(4.5)^{\prime}$ & $4(5.8)$ & $3(6.8)$ & $1(4.0)^{\prime}$ & $1.000^{\mathrm{a}}$ & $1.000^{\mathrm{a}}$ \\
\hline Hyperlipidemia (No.) (\%) & $4(18.2)$ & $13(18.8)$ & $8(18.2)$ & $5(20.0)$ & $1.000^{\mathrm{a}}$ & $1.000^{\mathrm{a}}$ \\
\hline Diabetes (No.) (\%) & $1(4.5)$ & $2(2.9)$ & $1(2.3)$ & $1(4.0)$ & $.569^{\mathrm{a}}$ & $1.000^{\mathrm{a}}$ \\
\hline Smoking status (No.) (\%) & $5(22.7)$ & $32(46.4)$ & $22(50.0)$ & $10(40.0)$ & $.080^{a}$ & $.461^{\mathrm{a}}$ \\
\hline
\end{tabular}

Note:-BMl indicates body mass index; NA, not applicable.

${ }^{a-c}$ The Fisher exact test (a), independent-samples Student $t$ test (b), and independent-samples Mann-Whitney $U$ test (c) were used to evaluate differences between MS and HC groups and between RRMS and PMS, as appropriate.

${ }^{d} P$ values $<.05$ were considered significant.

Wilk test, and CSA and $\triangle$ CSA data distributions were transformed if needed.

Group median and interquartile range (IQR) were computed for total CSA at baseline, total CSA at follow-up, and $\Delta$ CSA at each cervical level and for the whole-vessel (WV) course.

We tested these group comparisons: HC versus MS, RRMS versus $\mathrm{PMS}, \mathrm{MS}_{\mathrm{CVD}}$ versus $\mathrm{MS}_{\text {noCVD }}$, and $\mathrm{HC}_{\mathrm{CVD}}$ versus $\mathrm{HC}_{\text {noCVD }}$. Baseline-to-follow-up CSA differences between groups were assessed with linear mixed-model analysis. Group differences at the same time point and baseline-to-follow-up differences within each group were tested on the WV with mixedmodel analysis. At each cervical level, group differences were assessed for CSA at baseline, for CSA at follow-up, and for $\triangle \mathrm{CSA}$, either with the Mann-Whitney $U$ test for matched groups or with linear mixed-model analysis, correcting for the demographic or clinical nonmatching factors. To evaluate differences between baseline and follow-up CSA within each group at each cervical level, we used the related-samples Wilcoxon singed rank test. The Benjamini-Hochberg procedure was performed to correct for multiple comparisons.

More details about mixed-model analysis are reported in the On-line Appendix. $P$ values $<.05$ were considered significant.

\section{RESULTS}

\section{Demographic and Clinical Characteristics}

In total, 69 consecutive patients with MS (44 with RRMS and 25 with PMS, consisting of 23 with secondary-progressive and 2 with primary-progressive MS) and 22 age- and sex-matched HC were included in the study (Table 1). No significant differences in body mass index, prevalence of any CVD, and smoking status were observed between the MS and HC groups. There were significant differences between the RRMS and PMS subgroups regarding age $(P<.001)$, EDSS $(P<.001)$, disease duration $(P=.001)$, and the prevalence of hypertension $(P=.023)$. Fifty-five $(79.7 \%)$ of 69 patients were on disease-modifying therapy (29 on interferon $\beta$, 18 on glatiramer acetate, and 8 on natalizumab). Demographic and clinical information related to $\mathrm{MS}_{\mathrm{CVD}}, \mathrm{MS}_{\text {noCVD }}, \mathrm{HC}_{\mathrm{CVD}}$, and $\mathrm{HC}_{\text {noCvD }}$ subgroups are summarized in On-line Table 1.

\section{Assessment of CSA in MS and HC Groups}

All the acquired scans were classified as good-quality images. Online Fig 1 shows an example of the segmented regions of interest
(ROIs). Total CCA-ICA, VA, and IJV median CSA values at baseline and follow-up for the MS and $\mathrm{HC}$ groups and respective group-comparison results are reported in Table 2. The CSA-tosamples curves at baseline and at follow-up are shown for $\mathrm{HC}$ and patients with MS in Fig 1.

No significant differences were observed between MS and HC subjects in total CSA at baseline or at follow-up for any of the considered neck vessels. Furthermore, baseline-to-follow-up comparison between patients with MS and HC did not yield any significant differences.

In the MS group, significantly smaller total CSA at follow-up with respect to baseline was found for CCA-ICAs (C4: $P=.048$; C7: $P=$ .005 ; WV: $P=.012)$, for VAs (C3: $P=.028$; $4: P=.028$; $7: P=$ .028 ; WV: $P=.012)$, and for IJVs (C3: $P=.014$; C4: $P=.008$; C5: $P=.010 ; \mathrm{C} 6: P=.010 ; \mathrm{C} 7: P=.008 ; \mathrm{WV}: P=.002)$. No significant group differences were observed for CSA at baseline and follow-up or baseline to follow-up for any of the neck vessels or the cervical level in patients with MS with and without disease-modifying therapy.

HC showed significantly smaller total CSA at follow-up compared with baseline for only CCA-ICAs at the C7 level $(P=.03)$.

\section{Assessment of CSA in RRMS and PMS}

Neck vessel total CSA measures of RRMS and PMS and respective group comparison results are summarized in On-line Table 2. The CSA to sample curves at baseline and at follow-up are shown for RRMS and PMS in On-line Fig 2.

No significant CSA differences were found between RRMS and PMS groups at baseline or at follow-up. Furthermore, no significant baseline-to-follow-up differences between RRMS and PMS were observed.

Within the RRMS group, a significantly smaller CSA at follow-up with respect to baseline was observed for CCA-ICAs (C7: $P=.035)$, for VAs (WV: $P=.030$ ), and for IJVs (WV: $P=.032$ ).

The PMS group showed significantly reduced CSA at follow-up with respect to baseline for CCA-ICAs (WV: $P=.036$ ) and for IJVs (C4: $P=.040$; C5: $P=.040$; C6: $P=.040$; C7: $P=$ $.040 ; \mathrm{WV}: P=.021)$.

\section{Assessment of the CSA Association with CVD in MS and HC Groups}

No significant CSA differences between $\mathrm{MS}_{\mathrm{CVD}}$ and $\mathrm{MS}_{\text {noCVD }}$ were found at baseline (On-line Table 3). However, the CSA de- 
Table 2: Group medians and IQRs of neck vessel total cross-sectional area at baseline, and follow-up in HC $(n=22)$ and MS $(n=69)$ groups

\begin{tabular}{|c|c|c|c|c|c|c|c|c|c|}
\hline $\begin{array}{c}\text { Vessel/Cervical } \\
\text { Level }\end{array}$ & $\begin{array}{c}\text { HC BL CSA } \\
\left(\mathrm{mm}^{2}\right) \\
\text { (Median) } \\
\text { (IQR) }\end{array}$ & $\begin{array}{c}\text { MS BL CSA } \\
\left(\mathrm{mm}^{2}\right) \\
\text { (Median) } \\
\text { (IQR) }\end{array}$ & $\begin{array}{c}\text { BL CSA } \\
\text { MS vs HC } \\
\text { ( } P \text { Value) }\end{array}$ & $\begin{array}{l}\text { HC FU CSA } \\
\left(\mathrm{mm}^{2}\right) \\
\text { (Median) } \\
\text { (IQR) }\end{array}$ & $\begin{array}{l}\text { MS FU CSA } \\
\left(\mathrm{mm}^{2}\right) \\
\text { (Median) } \\
\text { (IQR) }\end{array}$ & $\begin{array}{c}\text { FU CSA } \\
\text { MS vs HC } \\
\text { ( } P \text { Value) }\end{array}$ & $\begin{array}{c}\text { HC CSA BL } \\
\text { vs FU ( } P \text { Value) }\end{array}$ & $\begin{array}{l}\text { MS CSA } \\
\text { BL vs FU } \\
\text { ( } P \text { Value) }\end{array}$ & $\begin{array}{c}\text { BL-to-FU MS vs } \\
\text { HC CSA } \\
\text { (P Value) }\end{array}$ \\
\hline \multicolumn{10}{|l|}{ CCA-ICAs } \\
\hline $\mathrm{C} 3$ & $67.5(28.1)$ & $54.5(28.3)$ & $.298^{a}$ & $75.6(30.7)$ & $57.6(32.9)$ & $.248^{\mathrm{a}}$ & $.223^{c}$ & $.993^{\mathrm{C}}$ & $.699^{\mathrm{e}}$ \\
\hline C4 & 73.4 (19.9) & $79.3(28.2)$ & $.298^{\mathrm{a}}$ & $73.2(12.9)$ & $77.5(27.3)$ & $.535^{\mathrm{a}}$ & $.57^{c}$ & $.048^{c, g}$ & $.365^{e}$ \\
\hline $\mathrm{C} 5$ & 69.7 (14.7) & 75.7 (20.9) & $.298^{a}$ & $67.0(7.9)$ & 70.9 (23.5) & $.248^{\mathrm{a}}$ & $.168^{c}$ & $.361^{c}$ & $.365^{\mathrm{e}}$ \\
\hline $\mathrm{C} 6$ & 66.7 (10.8) & 71.5 (16.7) & $.318^{\mathrm{a}}$ & $66.5(9.7)$ & $67.8(19.4)$ & $.474^{\mathrm{a}}$ & $.223^{c}$ & $.222^{c}$ & $.603^{e}$ \\
\hline $\mathrm{C} 7$ & $69.1(8.9)$ & $69.7(19.8)$ & $.795^{\mathrm{a}}$ & $66.3(7.9)$ & $66.5(20.3)$ & $.474^{\mathrm{a}}$ & $.030^{c, g}$ & $.005^{c, g}$ & $.36^{\mathrm{e}}$ \\
\hline WV & $68.8(16.4)$ & $71.8(26.2)$ & $.605^{b}$ & $68.1(15.8)$ & $69.0(26.7)$ & $.632^{\mathrm{b}}$ & $.206^{\mathrm{d}}$ & $.012^{\mathrm{d}, \mathrm{g}}$ & $.967^{f}$ \\
\hline \multicolumn{10}{|l|}{ VAs } \\
\hline C3 & $31.9(6.5)$ & $31.7(6.9)$ & $.597^{\mathrm{a}}$ & 28.7 (11.5) & $30.3(7.2)$ & $.718^{\mathrm{a}}$ & $.070^{c}$ & $.028^{c, g}$ & $.921^{\mathrm{e}}$ \\
\hline $\mathrm{C} 4$ & $30.1(8.5)$ & $30.0(5.9)$ & $.597^{\mathrm{a}}$ & $28.8(10.8)$ & $29.7(6.5)$ & $.779^{\mathrm{a}}$ & $.288^{\mathrm{C}}$ & $.028^{c, g}$ & $.921^{\mathrm{e}}$ \\
\hline $\mathrm{C} 5$ & $29.1(8.0)$ & $29.4(6.0)$ & $.597^{\mathrm{a}}$ & $29.4(10.6)$ & $29.4(6.3)$ & $.948^{a}$ & $.570^{c}$ & $.051^{\mathrm{C}}$ & $.921^{\mathrm{e}}$ \\
\hline $\mathrm{C} 6$ & $28.4(7.6)$ & $29.7(6.9)$ & $.588^{\mathrm{a}}$ & $27.6(8.4)$ & $28.9(7.0)$ & $.718^{\mathrm{a}}$ & $.570^{c}$ & $.051^{\mathrm{C}}$ & $.921^{\mathrm{e}}$ \\
\hline $\mathrm{C7}$ & $28.4(9.2)$ & $29.2(8.1)$ & $.588^{a}$ & $27.0(8.0)$ & $28.6(8.0)$ & $.718^{\mathrm{a}}$ & $.570^{c}$ & $.028^{c, g}$ & $.92^{\mathrm{e}}$ \\
\hline WV & $29.7(7.9)$ & $30.5(7.5)$ & $.406^{\mathrm{b}}$ & $28.5(9.8)$ & $29.6(7.9)$ & $.377^{\mathrm{b}}$ & $.119^{\mathrm{d}}$ & $.012^{\mathrm{d}, \mathrm{g}}$ & $.866^{f}$ \\
\hline \multicolumn{10}{|l|}{ IJVs } \\
\hline C3 & 100.8 (59.9) & 105.3 (59.7) & $.956^{\mathrm{a}}$ & $94.8(52.9)$ & $90.6(60.8)$ & $.970^{a}$ & $.444^{c}$ & $.014^{c, g}$ & $.987^{\mathrm{e}}$ \\
\hline C4 & 111.4 (44.8) & $121.8(67.9)$ & $.956^{\mathrm{a}}$ & $107.6(63.9)$ & $102.8(74.0)$ & $.970^{\mathrm{a}}$ & $.444^{c}$ & $.008^{c, g}$ & $.987^{\mathrm{e}}$ \\
\hline $\mathrm{C} 5$ & 117.1 (86.7) & $122.4(59.8)$ & $.956^{a}$ & 103.9 (89.3) & 107.9 (71.6) & $.970^{\mathrm{a}}$ & $.444^{c}$ & $.010^{c, g}$ & $.987^{\mathrm{e}}$ \\
\hline C6 & 116.7 (124.2) & $118.7(91.6)$ & $.956^{\mathrm{a}}$ & $86.7(120.0)$ & $101.4(86.9)$ & $.970^{a}$ & $.444^{c}$ & $.010^{c, g}$ & $.987^{\mathrm{e}}$ \\
\hline $\mathrm{C7}$ & 116.9 (174.2) & $126.3(95.4)$ & $.956^{a}$ & 109.4 (111.6) & 113.2 (90.7) & $.970^{a}$ & $.935^{c}$ & $.008^{\mathrm{c}, \mathrm{g}}$ & $.987^{\mathrm{e}}$ \\
\hline WV & 111.9 (87.0) & 119.5 (73.5) & $.790^{\mathrm{b}}$ & 99.3 (76.1) & 103.8 (76.4) & $.913^{\mathrm{b}}$ & $.424^{d}$ & $.002^{\mathrm{d}, \mathrm{g}}$ & $.680^{f}$ \\
\hline
\end{tabular}

Note:-BL indicates baseline; FU, follow-up.

${ }^{\mathrm{a}-\mathrm{f}}$ Group medians and IQR of neck vessel total CSA at baseline and follow-up are reported for HC and MS at each cervical level and for the WV course. To evaluate CSA differences between $\mathrm{HC}$ and MS groups at baseline and at follow-up, an independent-samples Mann-Whitney $U$ test (a) was used at each cervical level, while linear mixed models were used for the WV (b). To evaluate differences between baseline and follow-up within each group, the Wilcoxon signed-rank test (c) was used at each cervical level, while linear mixed models were used for the WV (d). To perform baseline-to-follow-up CSA comparison between groups, linear mixed models were used at each cervical level (e) and for the WV (f). The Benjamini-Hochberg procedure was performed to correct for multiple comparisons.

${ }^{\mathrm{g}}$ An $\alpha$ level of .05 was considered significant.
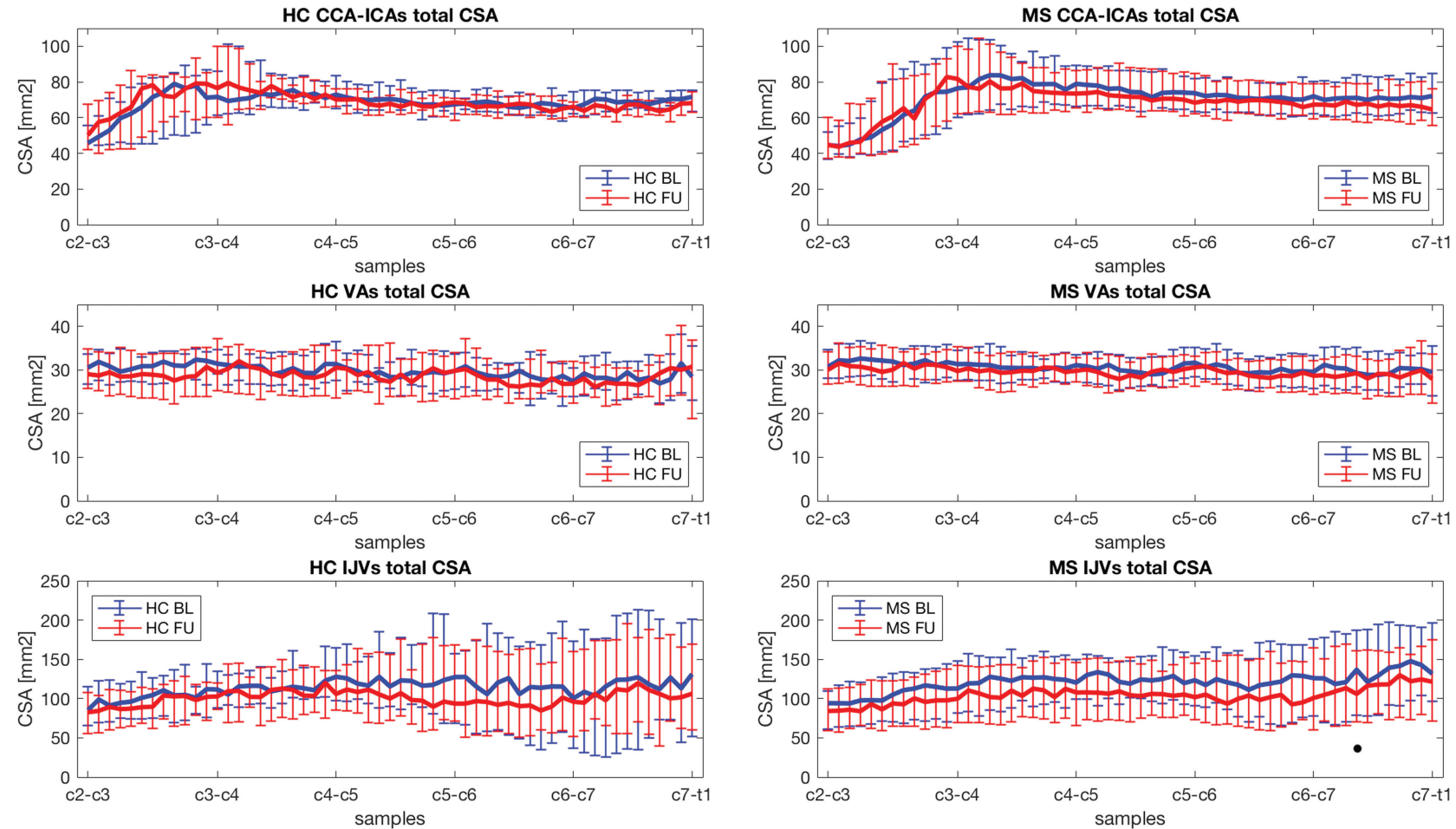

FIG 1. Total CSA of CCA-ICAs, VAs, and IJVs at baseline (blue) and at follow-up (red) for HC (left) and patients with MS (right). The median CSA values (lines) and the respective IQR (bars) are represented for all the samples along the C3-to-C7 cervical levels. BL indicates baseline; FU, follow-up.

creased with time, and $\triangle \mathrm{CSA}$ was significantly larger in $\mathrm{MS}_{\mathrm{noCVD}}$ with respect to $\mathrm{MS}_{\mathrm{CVD}}$ for IJVs $(\mathrm{C} 3: P=.018 ; \mathrm{C} 4: P=.018$; $\mathrm{C} 5$ : $P=.010 ; \mathrm{C} 6: P=.015 ; \mathrm{C} 7: P=.018$; WV: $P=.003)$. The CSA- to-samples curves at baseline and follow-up are shown for both subgroups in Fig 2. No significant group differences were observed for CSA at baseline and follow-up or baseline to follow-up 

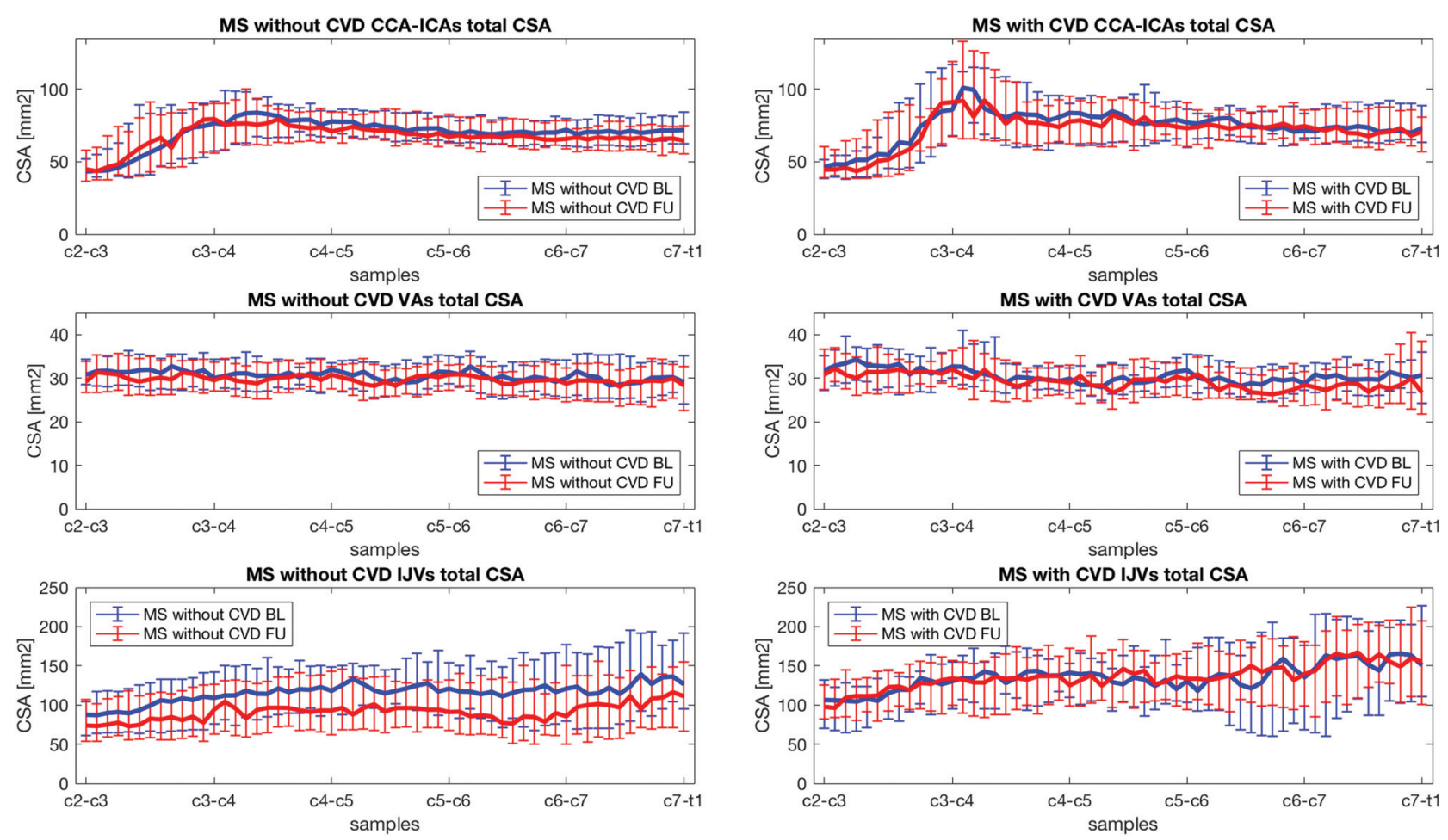

FIG 2. Total CSA of CCA-ICAs, VAs, and IJVs at baseline (blue) and at follow-up (red) for patients with MS without CVD (left) and for patients with MS with CVD (right). The median CSA values (lines) and the respective IQR (bars) are represented for all the samples along the C3-to-C7 cervical levels. BL indicates baseline; FU, follow-up.

for any of the neck vessels or cervical levels in patients with MS with $(n=32)$ and without $(n=37)$ smoking status.

Both CSA at baseline and $\triangle$ CSA were not significantly different between $\mathrm{HC}_{\mathrm{CVD}}$ and $\mathrm{HC}_{\text {noCVD }}$ (On-line Table 4).

\section{DISCUSSION}

To the best of our knowledge, this is the first longitudinal study assessing CCA-ICA, VA, and IJV CSA evolution across time in patients with MS. The main finding of this study is that a reduction of all major neck vessel CSA was observed during 5 years in patients with MS. A smaller CSA at follow-up was seen independent of disease phenotype and vascular comorbidity, while only sporadic changes were found for HC during the same time observation.

Most interesting, the CSA of both neck arteries for brain supply and veins for extracranial drainage was found to be affected at several cervical levels in patients with MS during the follow-up. A significant CSA decrease with time was also found in $\mathrm{HC}$ but only at the $\mathrm{C} 7$ cervical level for CCA-ICAs. Given the small sample size of $\mathrm{HC}$, this isolated difference should be interpreted with caution.

Despite the emerging effects of the role of cardiovascular comorbidities in contributing to MS disease severity, ${ }^{7,8,10-12}$ there is scarce evidence of the involvement of neck arterial structural changes. A recent study showed lower CCA-ICA and VA CSA in a group of 193 patients with MS compared with 193 HC. ${ }^{17}$ Furthermore, significantly higher carotid intima-media thickness was observed in MS without CVD with respect to HC, suggesting that patients with MS have a predisposition to atherosclerosis. ${ }^{24}$ Both MS and atherosclerosis are associated with an increase of plasma level of interleukin-6, tumor necrosis factor $\alpha$, monocyte chemoattractant protein-1, soluble intercellular adhesion molecule-1, vascular cell adhesion molecule 1 , and endothelial microparticles. ${ }^{25-29}$ In addition, the progression and severity of both diseases are known to be associated with lipoproteins and cholesterol metabolism. ${ }^{7,30,31}$ All this evidence and our results showing a consistent decrease of CCA-ICA and VA CSA with time in the MS group suggest that the 2 pathologies may share some mechanisms that cause or increase the inflammatory reaction.

The reduction of ICA and VA CSA may also be associated with hypoperfusion of normal-appearing brain tissue, which has been previously observed in MS. ${ }^{32,33}$ Although the clinical correlations between MS and perfusion alterations have not been strongly established, ${ }^{34}$ some studies showed an association between reduced gray matter cerebral blood flow, cognitive impairment, ${ }^{32}$ and fatigue, $^{35}$ while 1 study showed an inverse correlation between periventricular normal-appearing white matter CBF and EDSS. ${ }^{33}$ Because hypoperfusion was also observed in the absence of GM atrophy in early RRMS, ${ }^{32}$ it may not only be an epiphenomenon in MS. Longitudinal combined studies of neck vessel CSA, brain perfusion, and GM volume could help to clarify the link existing among these different types of alterations.

In this work, a significant and consistent reduction of CSA with time in MS was also observed for IJVs. This result must be interpreted against a background of conflicting findings. Some previous cross-sectional studies have shown a greater prevalence of morphologic and hemodynamic alterations of extracranial venous drainage pathways in patients with MS with respect to HC. ${ }^{14,16}$ On the other hand, some other studies reported an absence of significant differences between patients with MS and HC 
regarding IJV CSA and flow rates. ${ }^{15,36}$ Our results at baseline are in line with the latter group of findings. However, the IJV CSA changes that we observed longitudinally in this study in patients with MS may suggest a potential link between IJV CSA and the disease course. The clinical relevance of these observations remains elusive. Recently, extracranial venous angioplasty has been reported to be largely ineffective at impacting the course of $\mathrm{MS}^{37}$; therefore, caution should be used when drawing final conclusions. The investigation of fluid dynamics of the brain, including the recently discovered sinus-associated lymphatic vessels and the glymphatic pathways, may shed more light on the relation between vascular and immune/inflammatory factors in MS. ${ }^{38}$ By interpreting the obtained IJV CSA reduction together with the CSA decrease of neck arteries with time in MS, one could also explain a decrease in IJV CSA because of a potential flow reduction in CCA-ICA and VA pathways.

Cardiovascular risk factors and CVD are well-known to adversely affect the course of MS. ${ }^{1}$ Specifically, smoking was reported to be associated with increased BBB disruption, higher lesion volumes, greater brain atrophy, ${ }^{23}$ and more rapid conversion from RRMS to a PMS disease course. ${ }^{39}$ Obesity was shown to be linked with increased MS risk and higher disability. ${ }^{40}$ Also diabetes, hypertension, dyslipidemia, and ischemic heart disease are associated with worse disability and a more severe disease course, ${ }^{6,7}$ increased lesion burden, and more advanced brain atrophy. ${ }^{10,11}$ Nevertheless, in the present study, greater change of IJV CSA at all cervical levels was observed for $\mathrm{MS}_{\text {noCVD }}$ compared with $\mathrm{MS}_{\mathrm{CVD}}$. The limited sample size and the group inhomogeneity may have prevented us from highlighting CVD as an exacerbating factor for neck vessel CSA decrease. However, because CSA changes were also found in $\mathrm{MS}_{\text {noCvD }}$, neck vessel CSA reduction with time in MS might not be necessarily driven by CVD only. Investigating the effect of CVD and other potential MSrelated factors on CCA-ICA, VA, and IJV CSA in a larger cohort of subjects is warranted to make clearer speculations.

The relatively small sample size, especially of the HC group, is the main limit of this study, and it must be considered when interpreting our findings. Indeed, the comparison of neck vessel CSA between patients with MS and $\mathrm{HC}$ at baseline did not lead to any significant results, while a much larger recent study has reported a significantly lower CCA-ICA and VA CSA in patients with MS with respect to HC. ${ }^{17}$ Furthermore, no significant CSA differences were found between MS and HC subjects at follow-up as well as in baseline-to-follow-up comparisons, probably due to the discrepancies in sample size between patients with MS and HC groups. Nevertheless, the extensive longitudinal CSA change that we observed in the MS group for all the neck vessels indirectly corroborates the previous findings of neck vessel CSA alterations in MS. ${ }^{14,16}$

Other limitations are that TOF MR imaging signal depends on flow velocity and that by measuring CSA on TOF MRA axial slices, vessels are assumed to be perpendicular to the axial plane. Slow flow and the presence of blood refluxes might produce inaccurate CSA estimation; however, as opposed to contrast-enhanced MRA, TOF MR imaging has the advantage of imaging neck vessels in a noninvasive way. ${ }^{41}$ Furthermore, the assumption of the perpendicularity of the vessels to the axial plane was made for all vessels within the considered cervical levels; nevertheless, in future studies, CSA measures could be improved by considering the angle between the vessel longitudinal axis and the z-axis. Despite these limitations, the reliability and repeatability of the acquisition and segmentation methods used in this study were assessed and confirmed previously. ${ }^{22}$

To the best of our knowledge, this is the first longitudinal study assessing CCA-ICA, VA, and IJV CSA evolution with time in MS. The dependence of neck vessel CSA measures on many factors such as positioning, hydration, body mass index, and respiration have probably discouraged longitudinal evaluations so far. However, recent reports demonstrated the repeatability of neck vessel semiautomatic segmentation on TOF MRA images, ${ }^{21,22}$ making longitudinal studies feasible.

Future studies, involving larger groups of subjects and the acquisition of more data such as intima-media thickness measures, perfusion MR imaging, and GM volume should be performed to better understand these preliminary findings.

\section{CONCLUSIONS}

Patients with MS showed a decrease of CCA-ICA, VA, and IJV CSA during 5 years, regardless of the disease phenotype. Because neck vessel CSA evolution with time was found to be altered in MS even in the absence of CVD, CSA reduction might also be influenced by MS-related factors.

Disclosures: Giuseppe Baselli-UNRELATED: Employment: Politecnico di Milano, Comments: This work is part of my research duties as Full Professor of the Politecnico di Milano. Bianca Weinstock-Guttman-UNRELATED: Consultancy: Biogen Idec, Teva Pharmaceutical Industries, Novartis, Genentech, Celgene, EMD Serono; Grants/Grants Pending: Biogen, Teva Pharmaceutical Industries, Novartis, Genentech*; Payment for Lectures Including Service on Speakers Bureaus: Biogen, Teva Pharmaceutical Industries, Genentech. Robert Zivadinov-UNRELATED: Consultancy: Sanofi Genzyme, Novartis, Celgene, EMD Serono; Grants/Grants Pending: Biogen, Sanofi Genzyme, Novartis, Celgene, EMD Serono, Protembis*; Payment for Lectures Including Service on Speakers Bureaus: Sanofi Genzyme, Novartis, Celgene, EMD Serono. *Money paid to the institution.

\section{REFERENCES}

1. Spencer JI, Bell JS, DeLuca GC. Vascular pathology in multiple sclerosis: reframing pathogenesis around the blood-brain barrier. J Neurol Neurosurg Psychiatry 2018;89:42-52 CrossRef Medline

2. Rae-Grant AD, Wong C, Bernatowicz R, et al. Observations on the brain vasculature in multiple sclerosis: a historical perspective. Mult Scler Relat Disord 2014;3:156-62 CrossRef Medline

3. Haider L, Zrzavy T, Hametner S, et al. The topography of demyelination and neurodegeneration in the multiple sclerosis brain. Brain 2016;139:807-15 CrossRef Medline

4. Desai RA, Davies AL, Tachrount M, et al. Cause and prevention of demyelination in a model multiple sclerosis lesion. Ann Neurol 2016;79:591-604 CrossRef Medline

5. Marshall $\mathrm{O}, \mathrm{Lu} \mathrm{H}$, Brisset JC, et al. Impaired cerebrovascular reactivity in multiple sclerosis. JAMA Neurol 2014;71:1275-81 CrossRef Medline

6. Marrie RA, Rudick R, Horwitz R, et al. Vascular comorbidity is associated with more rapid disability progression in multiple sclerosis. Neurology 2010;74:1041-47 CrossRef Medline

7. Weinstock-Guttman B, Zivadinov R, Mahfooz N, et al. Serum lipid profiles are associated with disability and MRI outcomes in multiple sclerosis. J Neuroinflammation 2011;8:127 CrossRef Medline

8. Weinstock-Guttman B, Zivadinov R, Horakova D, et al. Lipid profiles are associated with lesion formation over 24 months in interferon- $\boldsymbol{\beta}$ treated patients following the first demyelinating event. J Neurol Neurosurg Psychiatry 2013;84:1186-91 CrossRef Medline 
9. Kowalec K, McKay KA, Patten SB, et al; CIHR Team in Epidemiology and Impact of Comorbidity on Multiple Sclerosis (ECoMS). Comorbidity increases the risk of relapse in multiple sclerosis: a prospective study. Neurology 2017;89:2455-61 CrossRef Medline

10. Kappus N, Weinstock-Guttman B, Hagemeier J, et al. Cardiovascular risk factors are associated with increased lesion burden and brain atrophy in multiple sclerosis. J Neurol Neurosurg Psychiatry 2016;87: 181-87 CrossRef Medline

11. Pichler A, Khalil M, Langkammer C, et al. The impact of vascular risk factors on brain volume and lesion load in patients with early multiple sclerosis. Mult Scler 2017 Oct 1. [Epub ahead of print] CrossRef Medline

12. Christiansen CF. Risk of vascular disease in patients with multiple sclerosis: a review. Neurol Res 2012;34:746-53 CrossRef Medline

13. Marcotti S, Marchetti L, Cecconi P, et al. An anatomy-based lumped parameter model of cerebrospinal venous circulation: can an extracranial anatomical change impact intracranial hemodynamics? BMC Neurol 2015;15:95 CrossRef Medline

14. Zamboni P, Galeotti R, Menegatti E, et al. Chronic cerebrospinal venous insufficiency in patients with multiple sclerosis. J Neurol Neurosurg Psychiatry 2009;80:392-99 CrossRef Medline

15. Zivadinov R, Lopez-Soriano A, Weinstock-Guttman B, et al. Use of $M R$ venography for characterization of the extracranial venous system in patients with multiple sclerosis and healthy control subjects. Radiology 2011;258:562-70 CrossRef Medline

16. Sethi SK, Utriainen DT, Daugherty AM, et al. Jugular venous flow abnormalities in multiple sclerosis patients compared to normal controls. J Neuroimaging 2015;25:600-07 CrossRef Medline

17. Belov P, Jakimovski D, Krawiecki J, et al. Lower arterial cross-sectional area of carotid and vertebral arteries and higher frequency of secondary neck vessels are associated with multiple sclerosis. AJNR Am J Neuroradiol 2018;39:123-30 CrossRef Medline

18. Zivadinov R, Ramasamy DP, Vaneckova M, et al. Leptomeningeal contrast enhancement is associated with progression of cortical atrophy in MS: a retrospective, pilot, observational longitudinal study. Mult Scler 2017;23:1336-45 CrossRef Medline

19. Zivadinov R, Ramasamy DP, Benedict RR, et al. Cerebral microbleeds in multiple sclerosis evaluated on susceptibility-weighted images and quantitative susceptibility maps: a case-control study. $R a$ diology 2016;281:884-95 CrossRef Medline

20. Lublin FD, Reingold SC. Defining the clinical course of multiple sclerosis: results of an international survey-National Multiple Sclerosis Society (USA) Advisory Committee on Clinical Trials of New Agents in Multiple Sclerosis. Neurology 1996;46:907-11 CrossRef Medline

21. Laganà MM, Pelizzari L, Scaccianoce E, et al. Assessment of internal jugular vein size in healthy subjects with magnetic resonance and semiautomatic processing. Behav Neurol 2016;2016:9717210 CrossRef Medline

22. Pelizzari L, Laganà MM, Jakimovski $\mathrm{D}$, et al. Neck vessel cross-sectional area measured with MRI: scan-rescan reproducibility for longitudinal evaluations. J Neuroimaging 2018;28:48-56 CrossRef Medline

23. Zivadinov R, Weinstock-Guttman B, Hashmi $\mathrm{K}$, et al. Smoking is associated with increased lesion volumes and brain atrophy in multiple sclerosis. Neurology 2009;73:504-10 CrossRef Medline

24. Yuksel B, Koc P, Kurtulus F, et al. Is multiple sclerosis a risk factor for atherosclerosis? Multiple Sclerosis Journal: Sage Publication LTD, London, England; 2016:455-455
25. Li J, Wang W, Han L, et al. Human apolipoprotein A-I exerts a prophylactic effect on high-fat diet-induced atherosclerosis via inflammation inhibition in a rabbit model. Acta Biochim Biophys Sin (Shanghai) 2017;49:149-58 CrossRef Medline

26. Hautecoeur P, Forzy G, Gallois P, et al. Variations of IL2, IL6, TNF alpha plasmatic levels in relapsing remitting multiple sclerosis. Acta Neurol Belg 1997;97:240-43 Medline

27. Dawson J, Miltz W, Mir AK, et al. Targeting monocyte chemoattractant protein-1 signaling in disease. Expert Opin Ther Targets 2003;7: 35-48 CrossRef Medline

28. Damotte V, Guillot-Noel L, Patsopoulos NA, et al; International Multiple Sclerosis Genetics Consortium, Wellcome Trust Case Control Consortium 2. A gene pathway analysis highlights the role of cellular adhesion molecules in multiple sclerosis susceptibility. Genes Immun 2014;15:126-32 CrossRef Medline

29. Chironi GN, Boulanger CM, Simon A, et al. Endothelial microparticles in diseases. Cell Tissue Res 2009;335:143-51 CrossRef Medline

30. Orekhov AN, Sobenin IA. Modified lipoproteins as biomarkers of atherosclerosis. Front Biosci (Landmark Ed) 2018;23:1422-44 CrossRef Medline

31. Uher T, Fellows K, Horakova D, et al. Serum lipid profile changes predict neurodegeneration in interferon- $\beta 1$ a-treated multiple sclerosis patients. J Lipid Res 2017;58:403-11 CrossRef Medline

32. Debernard L, Melzer TR, Van Stockum S, et al. Reduced grey matter perfusion without volume loss in early relapsing-remitting multiple sclerosis. J Neurol Neurosurg Psychiatry 2014;85:544-51 CrossRef Medline

33. Adhya S, Johnson G, Herbert J, et al. Pattern of hemodynamic impairment in multiple sclerosis: dynamic susceptibility contrast perfusion MR imaging at 3.0 T. Neuroimage 2006;33:1029-35 CrossRef Medline

34. Lapointe E, Li DK, Traboulsee AL, et al. What have we learned from perfusion MRI in multiple sclerosis? AJNR Am J Neuroradiol 2018; 39:994-1000 CrossRef Medline

35. Inglese M, Park SJ, Johnson G, et al. Deep gray matter perfusion in multiple sclerosis: dynamic susceptibility contrast perfusion magnetic resonance imaging at 3 T. Arch Neurol 2007;64:196-202 CrossRef Medline

36. Cocozza S, Canna A, Lanzillo R, et al. Lack of correlation between extracranial venous abnormalities and multiple sclerosis: a quantitative MRI study. Brit J Radiol 2016 Jun 27. [Epub ahead of print] CrossRef Medline

37. Zamboni P, Tesio L, Galimberti S, et al; Brave Dreams Research Group. Efficacy and safety of extracranial vein angioplasty in multiple sclerosis: a randomized clinical trial. JAMA Neurol 2018;75: 35-43 CrossRef Medline

38. Louveau A, Da Mesquita S, Kipnis J. Lymphatics in neurological disorders: a neuro-lympho-vascular component of multiple sclerosis and Alzheimer's disease? Neuron 2016;91:957-73 CrossRef Medline

39. Healy BC, Ali EN, Guttmann CR, et al. Smoking and disease progression in multiple sclerosis. Arch Neurol 2009;66:858-64 Medline

40. Kavak KS, Teter BE, Hagemeier J, et al. Higher weight in adolescence and young adulthood is associated with an earlier age at multiple sclerosis onset. Mult Scler 2015;21:858-65 CrossRef Medline

41. Lindsay AC, Biasiolli L, Knight S, et al. Non-invasive imaging of carotid arterial restenosis using $3 \mathrm{~T}$ cardiovascular magnetic resonance. J Cardiovasc Magn Reason 2014;16:5 CrossRef Medline 